\title{
Blockade of the c-Jun amino terminal kinase prevents crescent formation and halts established anti-GBM glomerulonephritis in the rat
}

\author{
Frank Y Ma ${ }^{1,3}$, Robert S Flanc ${ }^{1,3}$, Greg H Tesch ${ }^{1}$, Brydon L Bennett ${ }^{2}$, Glenn C Friedman ${ }^{2}$ and \\ David J Nikolic-Paterson ${ }^{1}$
}

\begin{abstract}
Macrophages induce acute renal injury in anti-glomerular basement membrane (GBM) glomerulonephritis. This operates, in part, via activation of the c-Jun amino terminal kinase (JNK) signaling pathway. However, it is unknown whether inhibition of JNK signaling is effective once the proinflammatory response is established in the injured kidney. This study examined whether blockade of JNK signaling could halt disease progression, including crescent formation, in a model of severe crescentic anti-GBM glomerulonephritis. WKY rats were immunized with sheep IgG and then injected with sheep anti-GBM serum (day 0). Animals were treated with the JNK inhibitor, CC-401, vehicle alone, or no treatment from day 7 until being killed on day 24 of disease. Untreated animals at day 7 showed significant proteinuria, focal glomerular lesions, marked glomerular macrophage and T-cell accumulation, and upregulation of proinflammatory mediators (TNF- $\alpha$, iNOS, MMP-12). Untreated and vehicle-treated groups displayed severe glomerulonephritis at day 24 with renal impairment and worsening proteinuria. These animals had severe glomerular lesions, with $60 \%$ of glomeruli exhibiting fibrocellular crescents, in association with increased macrophage and T-cell accumulation (including macrophage giant cells) and a further increase in mRNA levels of TNF- $\alpha$, iNOS, MMP-12, and TGF- $\beta 1$. In contrast, CC-401 treatment prevented renal impairment, suppressed proteinuria, and prevented severe glomerular and tubulointerstitial lesions, including crescent formation and granulomatous-like lesions. These protective effects were independent of glomerular macrophage and T-cell accumulation, and of the humoral immune response. CC-401 treatment inhibited expression of both pro- and antiinflammatory molecules (interleukin-10 and heme oxygenase-1). In addition, IL-1 induced MMP-12 and IL-10 production by cultured macrophages was found to be JNK dependent. In conclusion, blockade of JNK signaling provides substantial protection against the progression of crescentic anti-GBM glomerulonephritis, which may be, in part, due to inhibition of the macrophage proinflammatory response.
\end{abstract}

Laboratory Investigation (2009) 89, 470-484; doi:10.1038/labinvest.2009.2; published online 2 February 2009

KEYWORDS: JNK; macrophage; giant cell; MMP-12; myofibroblast.

The accumulation of monocyte/macrophages within the glomerulus and tubulointerstitium is associated with renal injury and the progression of many forms of human glomerulonephritis. ${ }^{1}$ Macrophage accumulation is most prominent in rapidly progressive forms of glomerulonephritis, and is a feature of crescent formation. ${ }^{2}$ Studies in human and experimental crescentic glomerulonephritis have identified a proinflammatory phenotype of the macrophage infiltrate in various glomerulonephridities on the basis of their production of proinflammatory mediators such as tumor necrosis factor- $\alpha$ (TNF- $\alpha)$, interleukin- $1 \beta$ (IL-1 $\beta)$, inducible nitric oxide synthase (iNOS), matrix metalloproteinase-12 (MMP-12), tissue factor, and reactive oxygen species. ${ }^{3-7}$ Indeed, blocking studies in animal models of antiglomerular basement membrane (GBM) glomerulonephritis have shown a functional role for a number of macrophage proinflammatory mediators in causing acute renal injury. ${ }^{6,8-10}$ Other aspects of the macrophage proinflammatory phenotype in crescentic glomerulonephritis include formation of macrophage giant cells in granulomatous-like lesions, ${ }^{11}$ and

\footnotetext{
${ }^{1}$ Department of Nephrology and Monash University Department of Medicine, Monash Medical Centre, Clayton, Victoria, Australia and ${ }^{2}$ Celgene, San Diego, CA, USA Correspondence: Dr DJ Nikolic-Paterson, PhD, Department of Nephrology, Monash Medical Centre, 246 Clayton Road, Clayton, Victoria 3168, Australia. E-mail: david.nikolic-paterson@med.monash.edu.au

${ }^{3}$ These authors contributed equally to this work.
}

Received 19 July 2008; revised 27 November 2008; accepted 5 December 2008 
expression of macrophage activation markers. ${ }^{12-14}$ Furthermore, activation of proinflammatory signaling pathways such as c-Jun amino terminal kinase (JNK) and p38 mitogen activated protein kinase, and activation of nuclear factor $\kappa-\mathrm{B}$ (NF- $\kappa \mathrm{B})$, has been described in human and experimental crescentic glomerulonephritis. ${ }^{15-18}$

Cells of the monocyte/macrophage lineage have the capacity to make a wide range of responses which is strongly influenced by the tissue microenvironment which they encounter. ${ }^{19}$ Monocyte/macrophages make a proinflammatory response on encountering the glomerular environment in anti-GBM glomerulonephritis. ${ }^{20}$ In contrast, macrophages can promote renal repair under different circumstances. ${ }^{21,22}$ Thus, modification of the macrophage proinflammatory response is a potential strategy to halt the progression of crescentic glomerulonephritis. ${ }^{23}$ Proof of principle of this approach has been demonstrated by recent adoptive transfer studies. Viral transduction to inhibit the NF- $\kappa$ B pathway in transferred macrophages resulted in suppression of the induction phase of rat anti-GBM glomerulonephritis, ${ }^{24}$ whereas alternative activation of transferred macrophages using the antiinflammatory cytokines, IL-4 and -13 , resulted in suppression of mouse adriamycin nephropathy. ${ }^{25}$ Therefore, there is considerable interest in seeking to 'switch off' the proinflammatory macrophage response in established renal injury as a strategy to halt the disease progression.

We have previously demonstrated that inhibition of JNK signaling can prevent the development of a macrophage proinflammatory response during the induction phase of anti-GBM glomerulonephritis in Sprague-Dawley rats using two different strategies. First, in a model in which renal injury is dependent on macrophage adoptive transfer, macrophage pretreatment with a specific JNK inhibitor did not affect macrophage recruitment into the glomerulus, but it markedly suppressed macrophage-mediated renal injury. ${ }^{26}$ Second, systemic administration of a specific JNK inhibitor in the induction phase of anti-GBM glomerulonephritis did not affect glomerular macrophage accumulation but it did prevent the induction of the macrophage proinflammatory response and suppressed the induction of renal injury. ${ }^{27}$

The aim of this study was to determine whether we could switch off an established proinflammatory response in the kidney by inhibiting JNK signaling and thereby halt disease progression in a model of severe crescentic anti-GBM glomerulonephritis.

\section{MATERIALS AND METHODS JNK Inhibitor}

The specific JNK inhibitor, CC-401, was synthesized by Celgene. CC-401 is a competitive inhibitor of the ATP binding site in the active, phosphorylated, form of JNK. This prevents JNK from phosphorylating its various target molecules, including the amino terminus of c-Jun. The efficacy and selectivity of this drug have been confirmed previously. ${ }^{27,28}$

\section{Animal Model of Anti-GBM Glomerulonephritis}

Female WKY rats (180-220g) were obtained from the Animal Resource Centre, Perth, Australia. All animal experimentation was approved by the Monash Medical Centre Animal Ethics Committee. Groups of 9 or 10 rats were immunized by subcutaneous injection of $5 \mathrm{mg}$ of sheep IgG in Freund's complete adjuvant followed 5 days later (termed day 0) by a tail vein injection of sheep anti-rat GBM serum. In this study, CC- $401(200 \mathrm{mg} / \mathrm{kg} / \mathrm{b}$.i.d. by oral gavage) or vehicle (sodium citrate) treatment was initiated in groups of 9 or 10 rats at 7 days after anti-GBM serum administration and continued twice daily thereafter until animals were killed at day 24. Additional groups of rats without treatment were killed at day 7 or day 24 after antiGBM serum injection as controls. Animals were housed in metabolic cages for 22 hours to collect urine on days 5, 14, and 21. Blood was collected at the time of death. Analysis of serum creatinine and urinary protein were performed by the Department of Biochemistry, Monash Medical Centre.

\section{Antibodies}

The primary antibodies used were rabbit anti- $\alpha 1$ tubulin (Abcam, Cambridge, MA, USA), mouse anti-CD68
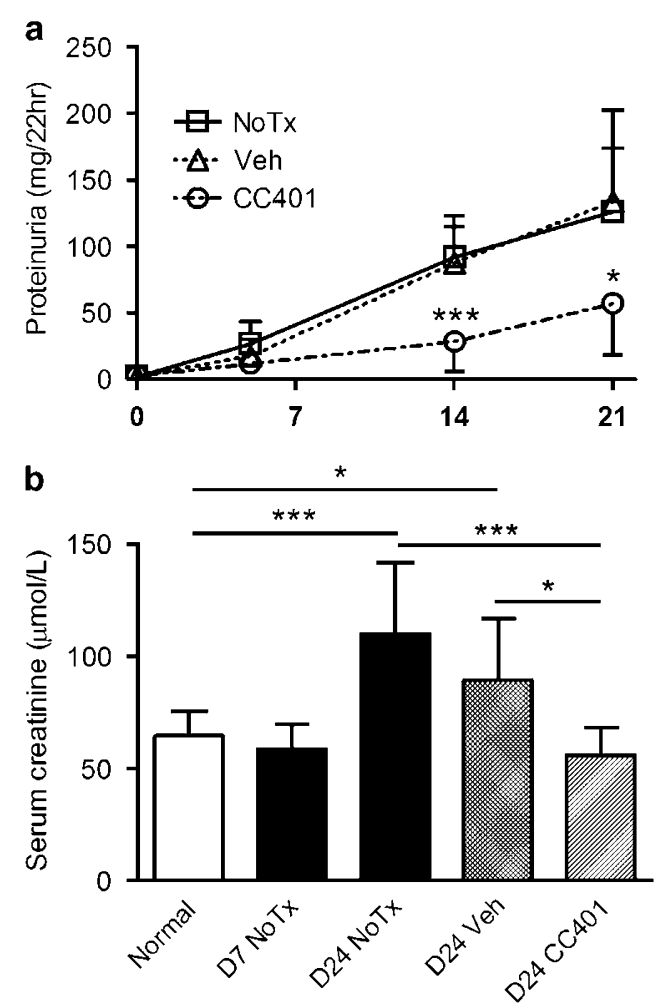

Figure 1 Proteinuria and renal function. CC-401 was given from day 7 to 24 of anti-GBM glomerulonephritis. (a) CC-401 treatment significantly reduced the degree of proteinuria compared to the vehicle and no-treatment groups on days 14 and 21. (b) CC-401 treatment prevented the significant increase in serum creatinine levels seen at day 24 in the vehicle and notreatment groups. ${ }^{\star} P<0.05$ and ${ }^{* *} P<0.001$. 

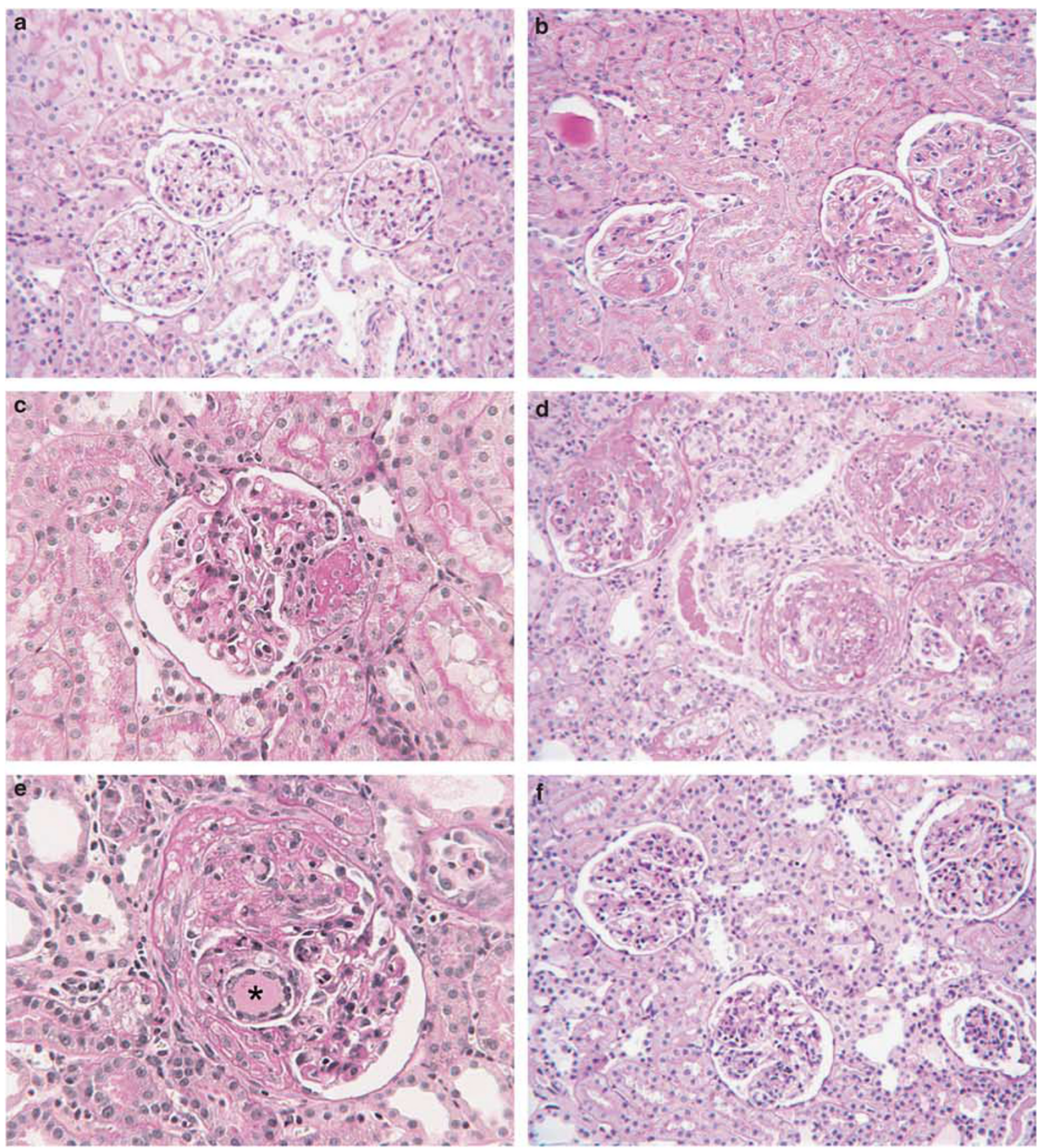

g

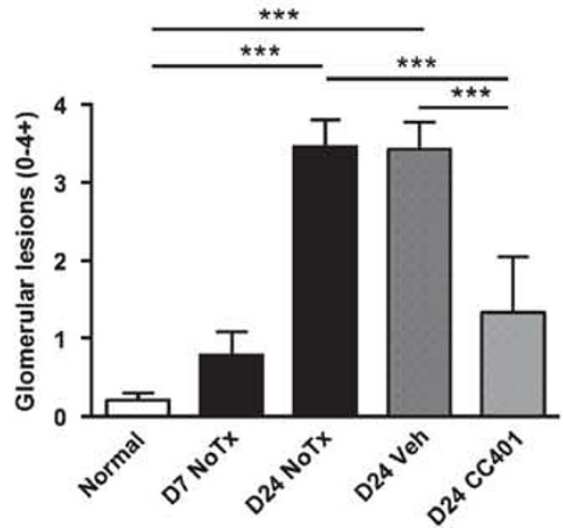

h

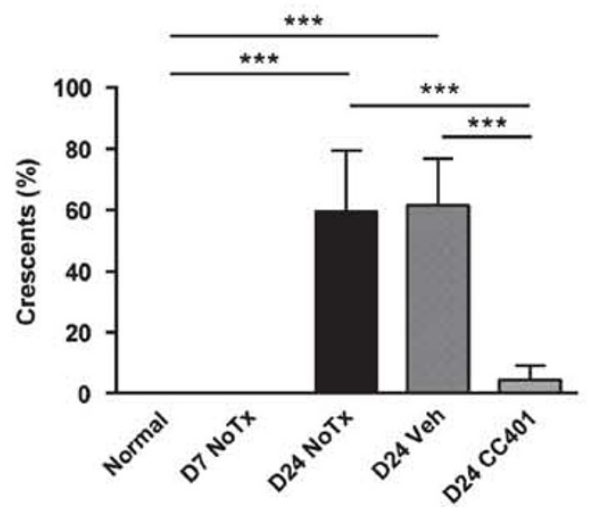


recognizing rat macrophages (ED1; Serotec, Oxford, UK), mouse anti-rat T-cell receptor (R73; Serotec), mouse antivimentin (Dako, Glostrup, Denmark), rabbit anti-phosphoc-Jun Ser63 (Cell Signaling, Danvers, MA, USA), rabbit antibody recognizing a C-terminal peptide of MMP-12 (Abgent, San Diego, CA, USA), mouse anti- $\alpha$-smooth muscle actin ( $\alpha$-SMA; Sigma-Aldrich, Castle Hill, NSW, Australia), mouse anti-fibrnectin (NeoMarker, Fremont, CA, USA), and goat anti-collagen IV (Santa Cruz Biotechnology, Santa Cruz, CA, USA). Biotinylated secondary antibodies used were goat anti-rabbit IgG, rabbit anti-goat IgG, rabbit antibodies reactive with rat IgG1, IgG2a, or IgG2b isotypes, and mouse antibodies reactive with total rat IgG (all from ZymedInvitrogen, Carlsbad, CA, USA). These biotinylated antibodies were detected with streptavidin-conjugated horseradish peroxidase (Zymed). Other secondary detection antibodies included horseradish peroxidase-conjugated goat anti-mouse IgG (Dako), peroxidase conjugated mouse antiperoxidase complexes (PAP; Dako), goat anti-rabbit Alexa Fluor 680 and donkey anti-mouse IRDye 800 (Molecular Probes, Eugene, OR, USA).

\section{Renal Histology}

Paraffin sections $(2 \mu \mathrm{m})$ of methylcarn-fixed tissue were stained using periodic acid Schiff's reagent (PAS) and hematoxylin. Glomerular lesions were analyzed under high power $(\times 400)$ on PAS stained sections. Each glomerulus within the section $(>50)$ was scored. Lesions within the glomerular tuft were defined by hyalinosis, focal and segmental adhesions, fibrinoid necrosis, atrophy, and sclerosis. Grading was based on the proportion of the glomerular tuft area involved in these lesions: 0 , no damage; $1+,<10 \% ; 2+, 10-25 \% ; 3+, 25-50 \% ; 4+,>50 \%$. The percentage of glomeruli exhibiting crescent formation was also assessed. Scoring was performed on blinded slides.

\section{Immunohistochemistry}

Immunoperoxidase staining for p-c-Jun Ser63 was performed on $4 \mu \mathrm{m}$ sections of formalin-fixed tissue using antigen retrieval (microwave oven heating in $0.1 \mathrm{M}$ sodium citrate $\mathrm{pH} 6.0$ for $10 \mathrm{~min}$ ) followed by a three-layer avidin-biotin peroxidase complex (ABC)-staining method. Immunoperoxidase staining for vimentin, ED1 + macrophages (with antigen retrieval), and $\alpha$-SMA was performed on formalinfixed tissue sections using a three-layer PAP staining method.
Immunoperoxidase staining for R73 + T cells was performed on tissue sections fixed in $2 \%$ paraformaldehyde-lysineperiodate with a three-layer PAP method. Immunoperoxidase staining for fibronectin and collagen IV was performed on methylcarn-fixed tissue sections using the $\mathrm{ABC}$ method. Glomerular accumulation of ED1 + macrophages was analyzed under high power $(\times 400)$ in 50 glomerular cross sections (gcs) per animal by image analysis using Image-Pro software (Media Cybernetics, Silver Springs, MD, USA ) and expressed as a percentage of the glomerular tuft area. The number of glomerular R73 $+\mathrm{T}$ cells was counted under high power $(\times 400)$ in 50 gcs per animal. Interstitial ED1 + and $\mathrm{R} 73+$ cells were counted in the entire cortex under high power fields $(\times 400)$. All scoring was performed on blinded slides.

\section{Urine Analysis of TNF- $\alpha$ and MMP-12}

Urine TNF- $\alpha$ levels were measured using an OptEIA rat TNF ELISA kit according to the manufacturer's protocol (BD Biosciences, San Diego, CA, USA). The presence of MMP-12 in urine was assessed by western blotting. Urine samples were diluted 1:1 with SDS-PAGE sample buffer (except for no-treatment and vehicle-treated day 24 anti-GBM disease urines, which were diluted 1:6 with sample buffer to reduce interference caused by the high levels of albumin) and analyzed by western blotting using an anti-MMP-12 antibody and the Odyssey infra-red system (described below). Recombinant MMP cocktail, containing MMP-12, was used as a positive control (R\&D Systems, Minneapolis, MN, USA).

\section{Real-Time RT-PCR}

Total RNA was extracted from whole kidney samples or cultured cells using the RiboPure reagent (Ambion Inc., Austin, TX, USA) and reverse transcribed using the Superscript First-Strand Synthesis kit (Invitrogen, Carlsbad, CA, USA) with random primers. Real-time PCR was performed on Rotor-Gene 3000 system (Corbett Research, Sydney, Australia) with thermal cycling conditions of $37^{\circ} \mathrm{C}$ for $10 \mathrm{~min}, 95^{\circ} \mathrm{C}$ for $5 \mathrm{~min}$, followed by 50 cycles of $95^{\circ} \mathrm{C}$ for $15 \mathrm{~s}$, $60^{\circ} \mathrm{C}$ for $20 \mathrm{~s}$, and $68^{\circ} \mathrm{C}$ for $20 \mathrm{~s}$. The primer pairs and FAM-labeled MGB probes used were iNOS (forward: TTCAGAGTCAAATCCTACCAAG; reverse: TGTGTTGTTGG GCTGGGAATA; probe: GAAAGAGGAAAAGGACA), TNF- $\alpha$ (forward: CTTATCTACTCCCAGGTTCTCT; reverse: TCTCC

Figure 2 Renal damage assessed on PAS-stained sections. (a) Normal rat kidney. (b) Day 7 of anti-GBM disease showing hypercellularity, glomerular enlargement, and focal glomerular lesions with a relatively preserved tubulointerstitium apart from occasional cast formation. (c) Day 7 of disease showing an individual glomerulus with focal glomerulosclerosis and tuft adhesion to Bowman's capsule suggesting an early stage of crescent formation. (d) Untreated day 24 of disease shows severe renal damage, including fibrocellular crescents, glomerular hyalinosis, segmental fibrinoid necrosis, and glomerulosclerosis. Tubular atrophy and dilation, cast formation, and focal and diffuse interstitial mononuclear cell infiltration is also evident. (e) Day 24 of untreated disease showing a single glomerulus featuring multinucleated giant cell formation $\left(^{*}\right)$, a fibrocellular crescent and damage of the capillary tuft. (f) CC-401 treatment at day 24 showing a histological picture very similar to that on day 7 of disease. Original magnification: a, b, d and f, $\times 250$; $\mathbf{c}$ and $\mathbf{e}, \times 400$. Graphs showing quantification of $(\mathbf{g})$ glomerular tuft lesions and $(\mathbf{h})$ the percentage of glomeruli with crescent formation. ${ }^{\star * *} P<0.001$. 

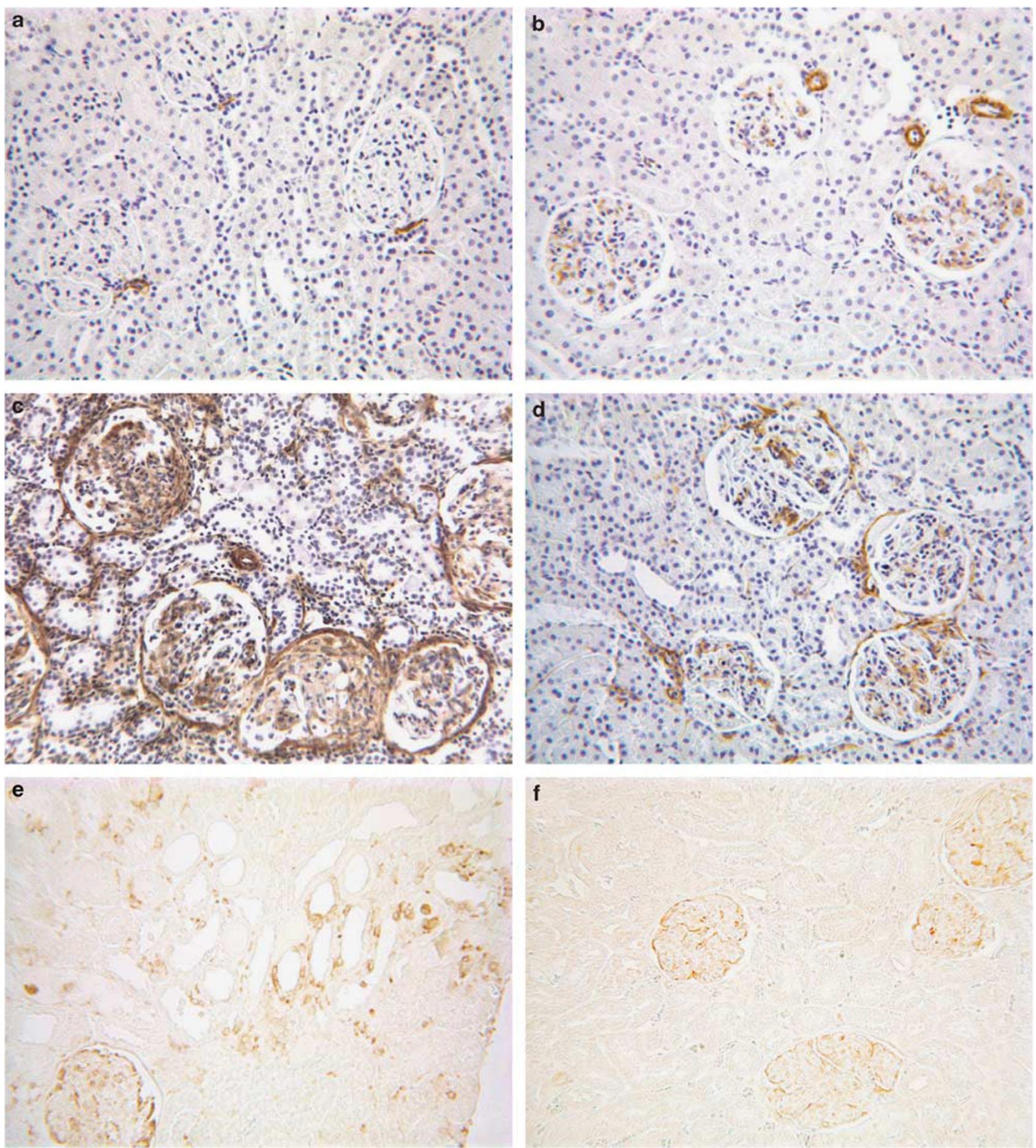

Figure 3 Myofibroblasts and tubular vimentin assessed by immunostaining. (a) Normal kidney showing $\alpha$-SMA staining restricted to vascular smooth muscle cells. (b) Day 7 of disease showing $\alpha$-SMA staining in glomeruli in a mesangial-like pattern. (c) Day 24 of untreated disease showing a dramatic accumulation of $\alpha$-SMA myofibroblasts in crescents and the periglomerular area. An increase in $\alpha$-SMA + cells is also evident in the capillary tuft and $\alpha$-SMA + myofibroblasts are evident in areas of tubulointerstitial damage. (d) Day 24 with CC-401 treatment shows $\alpha$-SMA staining limited to vascular smooth muscle cells and to a mesangial-like staining pattern in the glomerular tuft, presenting a picture very similar to that of untreated day 7 disease. Vimentin is expressed by glomerular podocytes in normal rat kidney and is absent from tubules (not shown). (e) Day 24 of untreated disease shows induction of vimentin staining in damaged tubules and in some interstitial cells, whereas glomerular vimentin staining is also seen (podocytes and possibly other glomerular cells). (f) Day 24 with CC-401 treatment shows vimentin staining in glomerular podocytes, but tubules lack vimentin staining. Original magnification: $\times 250$. 
TGGTATGAAATGGCAAA; probe: TCACCCACACCGTC $\mathrm{AG}$ ), transforming growth factor- $\beta 1$ (TGF- $\beta 1$; forward: GGACACACAGTACAGCAA; reverse: GACCCACGTAGTAG ACGAT; probe: ACAACCAACACAACCC), IL-10 (forward: TGGGAGAGAAGCTGAAGA; reverse: CATGGCCTTGTAG ACACCTTT; probe: GCAGTGGAGCAGGTGA), heme oxygenase-1 (HO-1; forward: GGAAGAGGAGATAGAGCGAAA; reverse: TGTGTGGCTGGTGTGTAA; probe: CCCCACTCTA CTTCCCT), rat MMP-12 (forward: GTCACAACAGTGGG AGATAA; reverse: GGCCACATGGAAGAAATTGAAG; probe: AGTCCAGCCACCAACA; collagen IV (forward: GGCGGTG CACAGTCAGACCAT; reverse: GGAATAGCCAATCCACAGT GA; probe: CAGTGCCCCAACGGT); MMP-9 (forward: CC TGCGTATTTCCATTCATCTT; reverse: TAACCATCCGAGC GACCTTT; probe: TCCTACTCTGCCTGCAC); human MMP-12 (forward: AACCAGTATTGGAGGTATGATG; reverse: GGTGATACGTTGGAGTAGGAAG; probe: GGAGACAGATGATGGAC). The relative amount of mRNA was calculated using comparative $\mathrm{Ct}(\Delta \Delta \mathrm{Ct})$ method. All specific amplicons were normalized against $18 \mathrm{~S}$ rRNA, which was amplified in the same reaction as an internal control using commercial assay reagents (Applied Biosystems, Scoresby, Vic, Australia).

\section{Cell Culture}

Human U937 monocytic cells were cultured and stimulated according to previously described methods. ${ }^{29}$ These cells were cultured in DMEM supplemented with $10 \%$ fetal calf serum, $100 \mathrm{U} / \mathrm{ml}$ penicillin, and $100 \mathrm{mg} / \mathrm{ml}$ streptomycin. After treatment with phorbol myristate acetate (PMA; Sigma; $100 \mathrm{ng} / \mathrm{ml}$ ) for 3 days, U937 cells were cultured in serum-free medium in the presence of GM-CSF ( $50 \mathrm{ng} / \mathrm{ml}$; Pepro Tech) and stimulated with IL-1 $\beta(100 \mathrm{U} / \mathrm{ml}$; Chemicon) for $24 \mathrm{~h}$ (mRNA analysis) or $48 \mathrm{~h}$ (western blot analysis). The role of JNK signaling in IL-1 induction of MMP-12 production was determined by preincubating these cells with $4 \mu \mathrm{M}$ CC-401 for $30 \mathrm{~min}$ before IL- $1 \beta$ stimulation. This dose has previously been shown to selectively inhibit JNK signaling in vitro. ${ }^{30}$ RNA extraction and real-time RT-PCR was performed as described above. Western blotting for MMP-12 was performed using a method previously described.$^{30}$ Briefly, cells were lysed in urea-RIPA buffer ( $\mathrm{pH}$ 7.2), lysate samples separated by SDS-PAGE and electroblotted onto nitrocellulose membranes. Blots were incubated with MMP-12 antibody overnight at $4^{\circ} \mathrm{C}$ in $1 \%$ blocking buffer (LiCor Biosciences, Lincoln, NE, USA), washed, then incubated with Alexa Fluor 680 goat anti-rabbit antibody and analyzed by the Odyssey infra-red imaging system (LiCor Biosciences). Blots were reprobed for $\alpha 1$-tubulin as a loading control. Results were quantified using the Gel-Pro Analyzer program (Media Cybernetics).

RAW 264.7 mouse macrophages were routinely cultured in DMEM with $10 \%$ FCS plus $100 \mathrm{U} / \mathrm{ml}$ penicillin, and $100 \mathrm{mg} /$ $\mathrm{ml}$ streptomycin. For experiments, RAW cells were cultured in serum-free media for $8 \mathrm{~h}$, incubated with $4 \mu \mathrm{M} \mathrm{CC}-401$ for
$30 \mathrm{~min}$, and then stimulated (or not) for $16 \mathrm{~h}$ with $10 \mathrm{ng} / \mathrm{ml}$ mouse IL-1 $\beta$ (Pepro Tech). RNA was then extracted from the cells and real-time RT-PCR performed to analyze IL-10 mRNA levels.

\section{Statistical Analysis}

Data are presented as mean \pm 1 s.d. Analysis between groups of animals was performed by parametric ANOVA using Newman-Keuls's posttest for multiple comparisons. Nonparametric data was analyzed by the Kruskal-Wallis ANOVA by ranks using Dunn's posttest for multiple comparisons (GraphPad 4.0 Software, San Diego, CA, USA).

\section{RESULTS \\ Proteinuria and Renal Function}

All animals developed significant proteinuria by day 5 after administration of anti-GBM serum (Figure 1a), with no differences between the various groups. The vehicle and no-treatment groups showed a progressive increase in the severity of proteinuria with time. CC- 401 treatment from days 7 to 24 slowed the progression of proteinuria, which was significantly reduced compared to the no-treatment and vehicle groups at days 14 and 21 (Figure 1a). However, there was still an increase in the degree of proteinuria at day 21 in CC-401-treated rats compared to proteinuria at day 5 . The vehicle and no-treatment groups developed renal impairment at day 24 as shown by an increase in serum creatinine. This was prevented by CC-401 treatment (Figure 1b).

\section{Renal Pathology}

Glomerular hypercellularity, increased glomerular size, and focal glomerular lesions featuring hyalinosis and atrophy were evident on day 7 of anti-GBM glomerulonephritis (Figure 2b). Some glomeruli at day 7 exhibited focal adhesion of the damaged tuft to Bowman's capsule indicating an early stage of crescent formation (Figure 2c), whereas there was relatively little tubulointerstitial damage beyond small numbers of protein casts. Mesangial cell activation was apparent in most glomeruli on day 7 of anti-GBM disease as shown by the mesangial pattern of $\alpha$-SMA staining in the glomerular tuft (Figure 3b).

The vehicle and no-treatment groups developed severe renal pathology by day 24 of anti-GBM disease, with $60 \%$ of glomeruli exhibiting crescent formation. Most crescents were fibrocellular in nature, with numerous $\alpha$-SMA + myofibroblasts present within crescents and in a dense layer around Bowman's capsule (Figures 2d and 3c). Deposition of fibronectin and collagen IV was prominent in crescents, as well as in the periglomerular area (Figure 4). Granulomatous-like lesions containing multinucleated giant cells were seen in crescents and in the glomerular tuft (Figure 2e), indicating aggressive cell-mediated immunity. Most glomeruli with crescents exhibited disruption of Bowman's capsule, which was accompanied by mononuclear cell infiltration. Severe lesions in the glomerular tuft, including fibrinoid 


\section{Fibronectin}
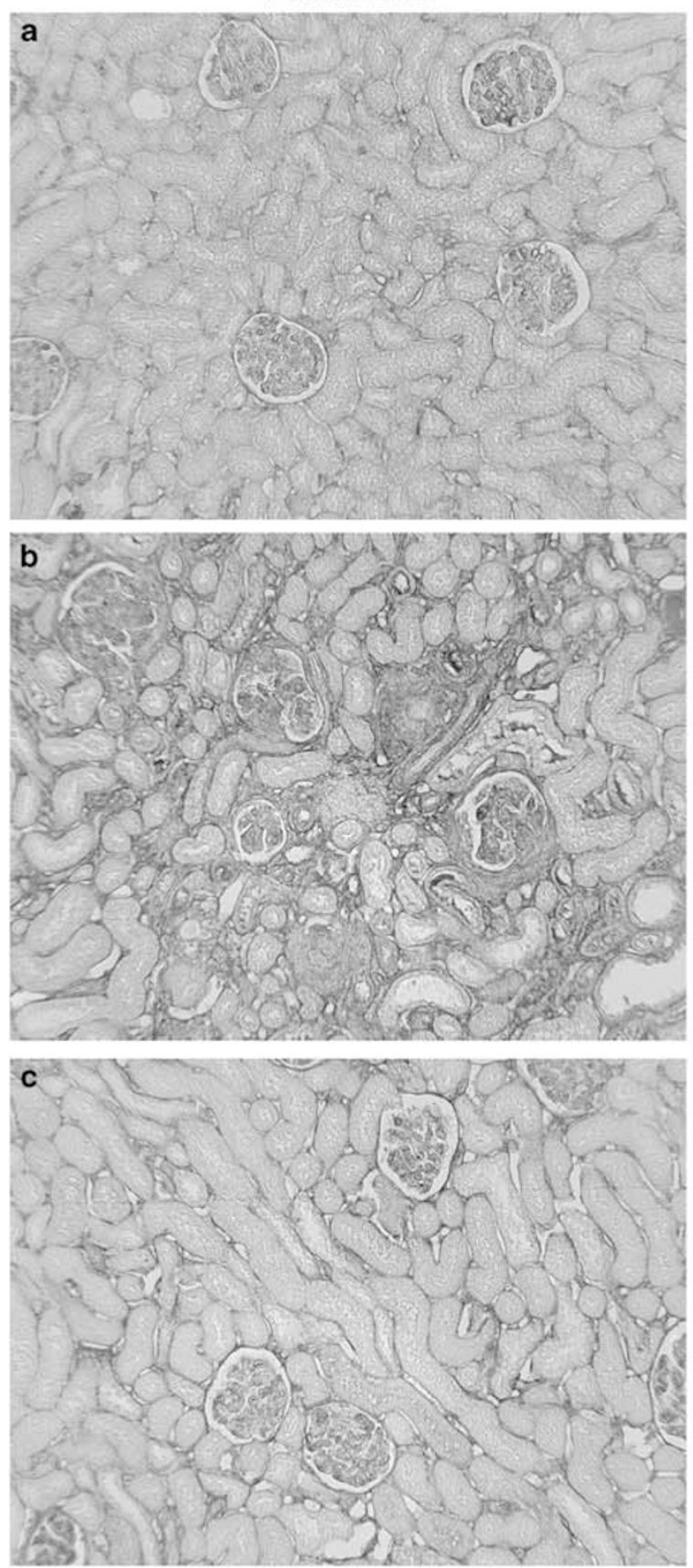

g

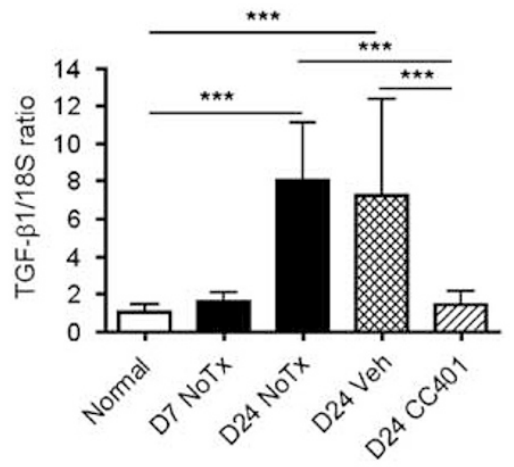

Collagen IV
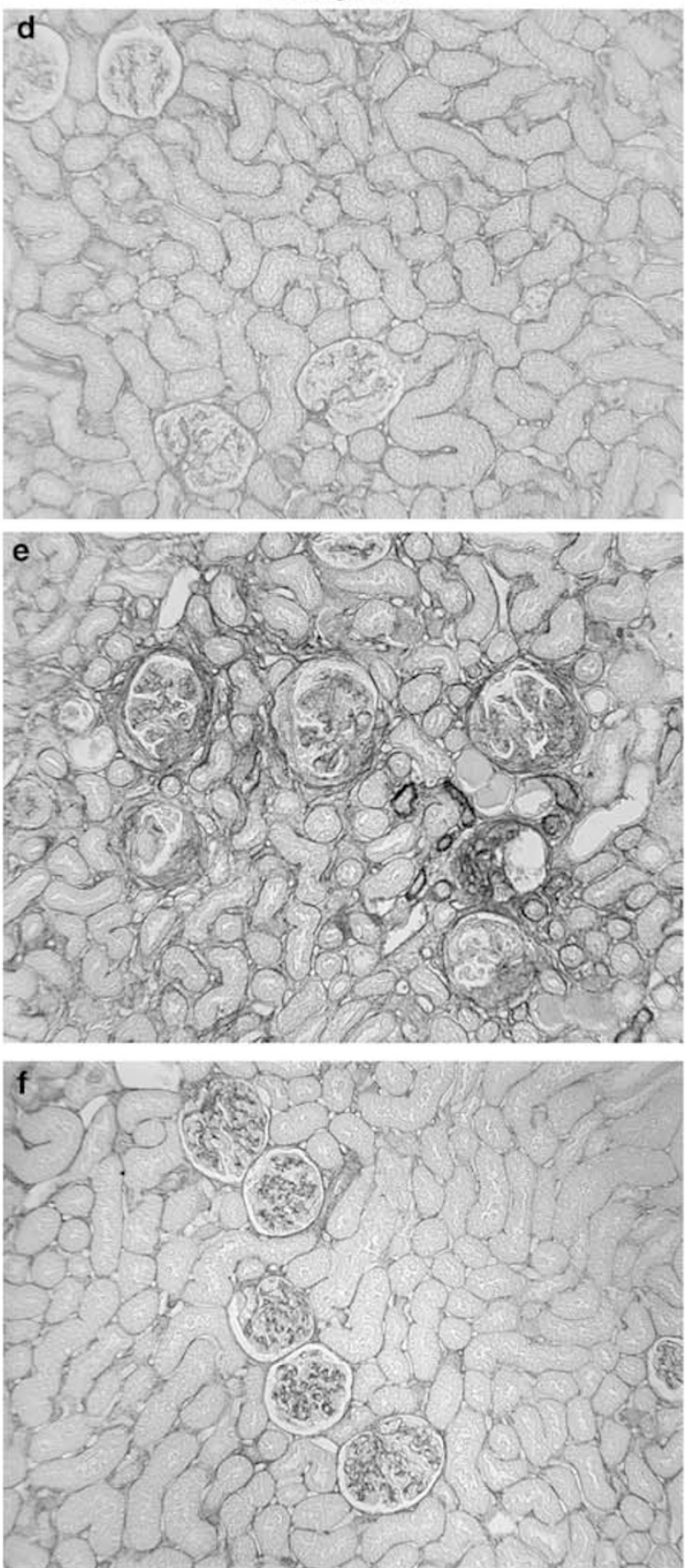

h

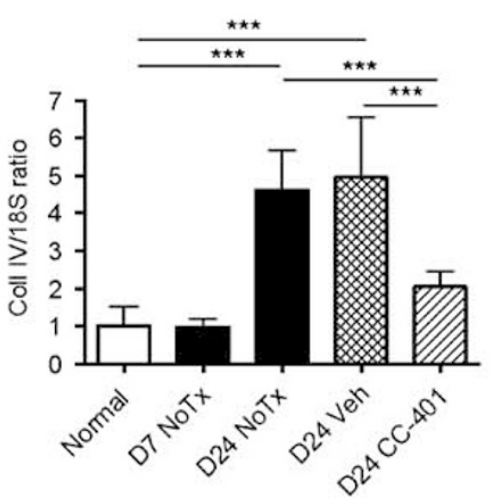


necrosis, atrophy, and sclerosis, were evident at day 24 (Figure $2 \mathrm{~d}$, e and g). Indeed, many $\alpha$-SMA + myofibroblasts were present in the glomerular tuft in association with marked deposition of fibronectin and collagen IV (Figures 3c and 4). Substantial tubulointerstitial damage was also evident at day 24 with tubular atrophy and dilatation, prominent cast formation, and focal and diffuse mononuclear cell infiltrates, including some granulomatous-like lesions containing multinucleated giant cells. The development of interstitial fibrosis was shown by deposition of fibronectin and collagen IV in association with accumulation of interstitial $\alpha$-SMA + myofibroblasts (Figures $3 \mathrm{c}$ and 4 ). Consistent with the histological evidence of glomerular and interstitial fibrosis, analysis of whole kidney tissue showed a significant increase in collagen IV and TGF- $\beta 1$ mRNA levels on day 24 of antiGBM disease (Figure 4). In addition, the induction of tubular vimentin expression was consistent with tubular damage and dedifferentiation (Figure 3e).

CC-401 treatment from days 7 to 24 resulted in profound protection from histological damage. Crescent formation was almost entirely prevented, with only $4.4 \%$ of glomeruli showing small cellular crescents. CC-401 treatment also prevented progressive lesions of the glomerular tuft and tubulointerstitium, including an absence of multinucleated giant cells, providing a histological picture very similar to that present on day 7 of disease when drug treatment was initiated. Immunostaining for $\alpha$-SMA showed that mesangial cell activation was still evident in CC-401-treated animals, but there was a profound reduction in myofibroblasts in Bowman's space, around Bowman's capsule, and in the interstitium. This was associated with prevention of glomerular and interstitial fibrosis as assessed by fibronectin and collagen IV immunostaining and preventing upregulation of collagen IV and TGF- $\beta 1$ mRNA levels (Figures $3 \mathrm{~d}$ and 4 ). In addition, tubular vimentin expression was largely absent, consistent with protection from tubular damage (Figure 3f).

\section{JNK Activation}

JNK is defined by its ability to phosphorylate the amino terminal domain of c-Jun at serines 63 and 73. As CC-401 does not prevent JNK phosphorylation, we utilized immunostaining for p-c-Jun Ser63 as a read out of JNK activity in renal tissue. Normal rat kidney shows almost no p-c-Jun + cells. On day 7 of anti-GBM disease, nuclear p-c-Jun staining was evident in cells of the glomerular tuft and in some tubules (Figure 5b). Widespread p-c-Jun stain- ing was evident on day 24 of disease, being present in cells of crescents, the glomerular tuft, numerous tubular epithelial cells, and some interstitial cells (Figure $5 \mathrm{c}$ and d). Furthermore, a novel observation was the demonstration of p-c-Jun staining in multinucleated giant cells in granulomatous-like lesions (Figure 5e). CC-401 treatment was highly effective in suppressing JNK signaling as shown by the lack of p-c-Jun staining in renal tissue at day 24 (Figure 5f).

\section{Adaptive Immune Response}

The adaptive immune response plays a critical role in the autologous phase in this passive transfer model of crescentic anti-GBM glomerulonephritis. ${ }^{31}$ Immunofluorescence staining found no difference in the intensity of glomerular deposition of sheep IgG, rat IgG, or rat C3 on day 24 of disease (data not shown). Similarly, there was no difference between the vehicle, CC-401, and no-treatment groups in the serum titer of rat IgG reactive with sheep IgG in both the total rat IgG response and in the IgG1-, IgG2a-, and IgG2bsubtype responses (data not shown). Furthermore, the glomerular T-cell infiltrate was not affected by CC-401 treatment (Figure 6g). However, the marked interstitial T-cell infiltrate that developed over days 7 to 24 was significantly reduced by CC- 401 treatment (Figure 6h), a finding consistent with protection against tubulointerstitial damage.

\section{Macrophage Accumulation and the Proinflammatory Response}

A prominent glomerular macrophage infiltrate was evident on day 7 of anti-GBM disease (Figure 6a and e). Analysis of whole kidney RNA showed an increase in iNOS, TNF- $\alpha$, and MMP-12 mRNA levels at this time, indicative of an established macrophage proinflammatory response. By day 24 of disease, there was a further increase in the number of macrophages within the glomerular tuft and the presence of many macrophages in crescents, the periglomerular area and throughout the interstitium (Figure 6b, c and e). Indeed, the presence of granulomatous lesions containing macrophage multinucleated giant cells was a feature of severe glomerular lesions (Figure 6c). There was a significant increase in mRNA levels for iNOS, TNF- $\alpha$ and MMP-12 from days 7 to 24 of anti-GBM disease (Figure 7). The increase in mRNA levels of these proinflammatory molecules was supported by analysis of urinary proteins. Western blotting identified urinary excretion of MMP-12 on day 24 of anti-GBM disease in the no-treatment (Figure 8a) and vehicle-treated groups

Figure 4 Renal fibrosis assessed by immunostaining and real-time RT-PCR. (a) Normal kidney showing fibronectin staining in glomeruli and the interstitium. (b) Day 24 of untreated disease showing a marked increase in fibronectin staining in the glomerular tuft, in crescents and the periglomerular area, and in the interstitium. (c) Day 24 with CC-401 treatment shows slightly increased glomerular fibronectin staining, but no change in interstitial fibronectin staining compared to normal kidney. (d) Normal kidney with collagen IV staining in glomeruli and the interstitium. (e) Day 24 of untreated disease shows a clear increase in collagen IV deposition in the glomerular tuft, crescents, the periglomerular area, and the interstitium. (f) Day 24 with CC-401 treatment shows a mild increase in glomerular collagen IV staining, whereas the interstitium shows no change compared to normal kidney. Graphs show relative quantification

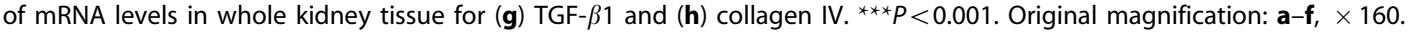


a

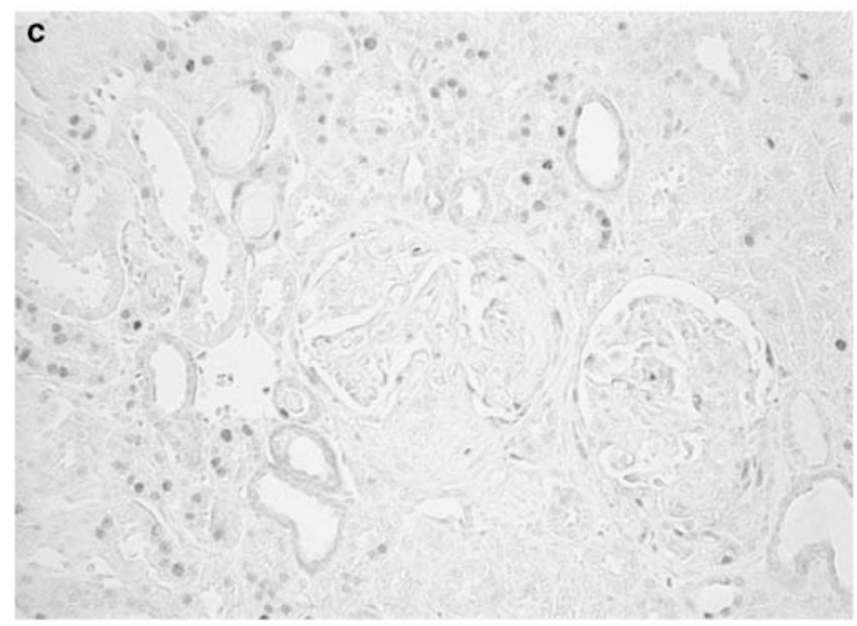

e

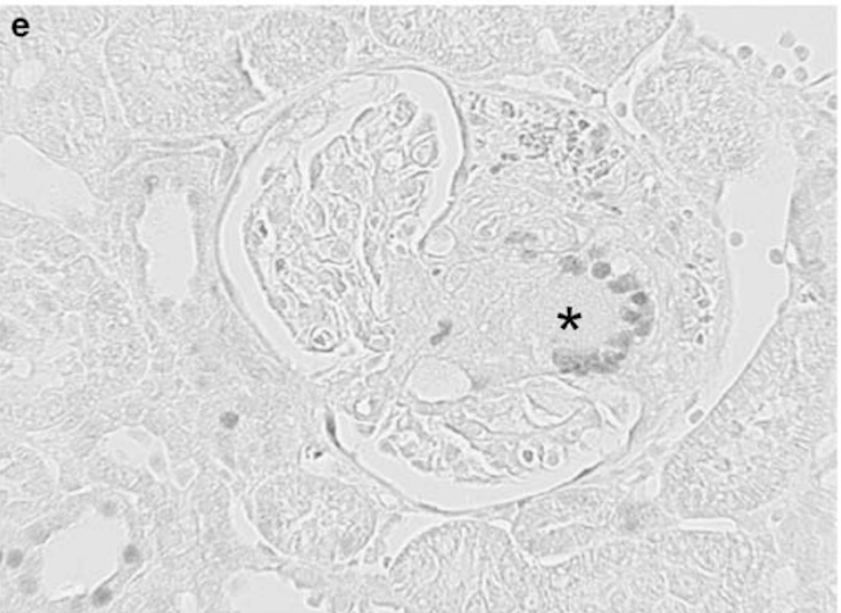

b
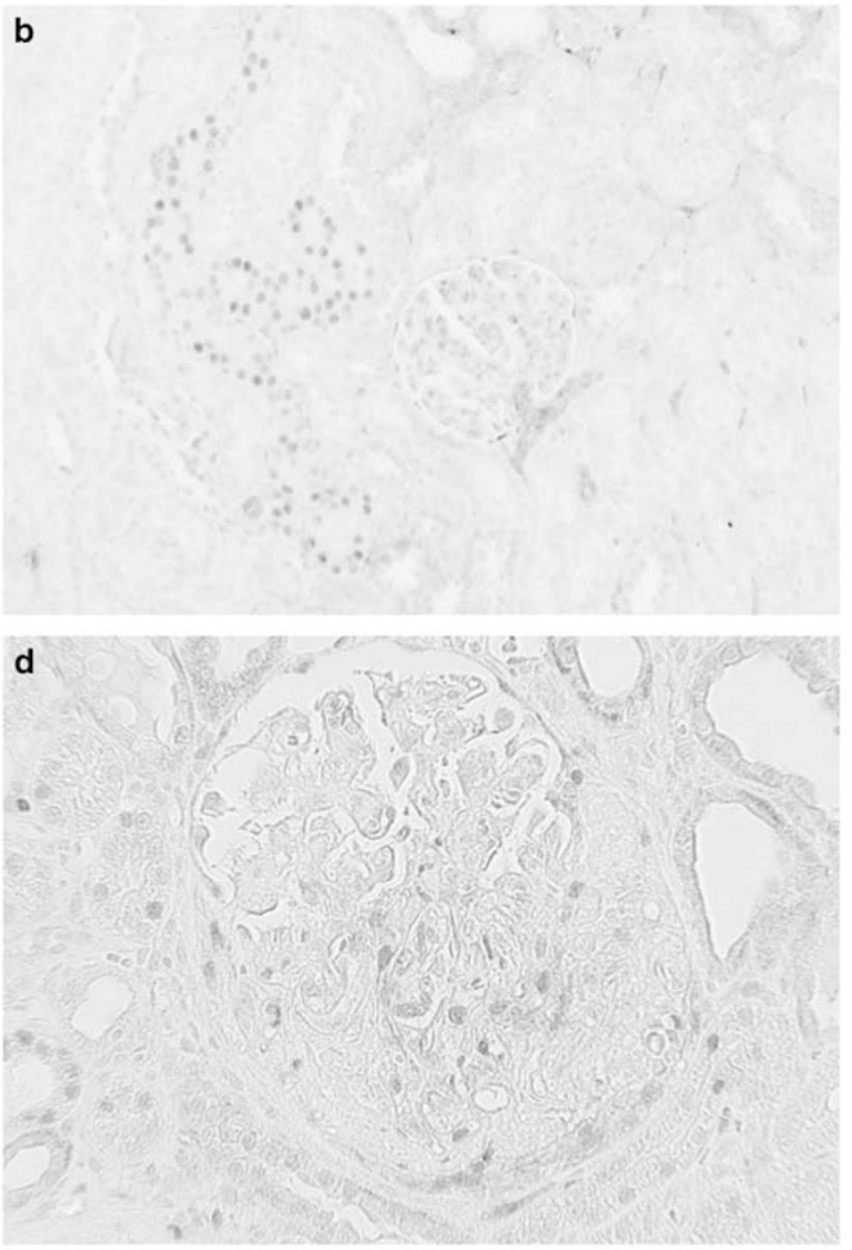

f

Figure 5 c-Jun phosphorylation assessed by immunostaining. (a) No p-c-Jun serine 63 staining is evident in normal kidney. (b) Day 7 of untreated disease shows nuclear staining in some glomerular cells and in some tubular epithelial cells. (c) Day 24 of untreated disease showing p-c-Jun + cells in the glomerular tuft, in crescents, in many tubular epithelial cells and in some interstitial cells. (d) A high-power view of a single glomerulus on day 24 of untreated disease shows nuclear p-c-Jun staining of cells in the capillary tuft and in the crescent. (e) A high power view on day 24 of untreated disease shows p-c-Jun staining in a multinucleated giant cell in a glomerular crescent $\left(^{*}\right)$. (f) Day 24 of disease showing that CC-401 treatment blocked c-Jun phosphorylation. Note, weak background staining of the arterial wall can be seen in (a, b and f). Original magnification: $\mathbf{a}, \mathbf{b}, \mathbf{c}, \mathbf{f}, \times 250$; d and $\mathbf{e}, \times 400$. 
(not shown). MMP-12 was absent from normal rat urine (Figure 8a), and was detected as a weak band in some animals on day 7. Significant TNF- $\alpha$ urinary excretion was seen on day 7 with increased levels on day 24 of anti-GBM disease (Figure $8 \mathrm{~b}$ ). This increase in iNOS and TNF- $\alpha$ mRNA levels is probably due to both the increased macrophage infiltrate and the expression by damaged tubular epithelial cells seen at day 24. However, the upregulation of MMP-12 mRNA on day 24 is likely to be macrophage specific because previous studies have localized MMP-12 production exclusively to macrophages in this disease model. ${ }^{6}$ Furthermore, there was little change in MMP-9 mRNA levels in anti-GBM disease (Figure 7), and no change in MMP-3 mRNA levels (data not shown).

CC-401 treatment from days 7 to 24 had no effect on macrophage accumulation within the glomerular tuft (Figure $6 \mathrm{~d}$ and e). However, macrophage accumulation in Bowman's space and in the periglomerular area was largely prevented, including an absence of multinucleated giant cells, and there was a major reduction in the number of interstitial macrophages (Figure 6d and f). Furthermore, CC-401 treatment caused a marked reduction in TNF- $\alpha$, iNOS, and MMP-12 mRNA levels compared to vehicle and no-treatment groups (Figure 7). Consistent with the mRNA analysis, CC-401 treatment significantly reduced urine TNF- $\alpha$ levels, whereas MMP-12 protein could not be detected in the urine of day 24 CC-401-treated animals even though this loading was six times greater than the day 24 vehicle and no-treatment groups (Figure 8).

Of note, renal MMP-12 mRNA and urine MMP-12 protein levels were highly sensitive to JNK blockade, returning to baseline values on day 24 of disease. To examine whether JNK signaling plays a direct role in MMP-12 expression, we examined the U937 monocyte cell line in vitro. As shown in Figure 9, IL-1 induced upregulation of MMP-12 mRNA and protein levels was inhibited by CC-401 indicating its dependence on JNK signaling.

Finally, we examined whether the protective effects of CC-401 treatment could be due to upregulation of antiinflammatory molecules. Macrophages can express high levels of IL-10 and heme oxygenase-1, both of which have been shown to promote resolution of the inflammatory response. ${ }^{32,33}$ There was a significant increase in IL-10 and HO-1 levels in vehicle and no-treatment groups over days 7-24 of disease. However, this increase in IL-10 was prevented by CC- 401 treatment, whereas the increased HO-1 mRNA levels were unaltered (Figure 7e and f). In addition, studies using the mouse RAW246.7 macrophage cell line demonstrated that IL-1 induced upregulation of IL-10 was JNK dependent (Figure 9d).

\section{DISCUSSION}

This study has shown that blockade of JNK signaling can suppress progressive renal injury in a model of severe crescentic anti-GBM glomerulonephritis. Several possible mechanisms for this protective effect are considered below.
The first possible mechanism by which JNK blockade halted progression of anti-GBM glomerulonephritis is through inhibition of the macrophage proinflammatory response. JNK blockade resulted in a marked reduction in the gene expression of a range of proinflammatory mediators (TNF- $\alpha$, iNOS, and MMP-12), which was also confirmed by a reduction in urinary excretion of TNF- $\alpha$ and MMP- 12 proteins. MMP-12 expression has been shown to be restricted to glomerular macrophages and macrophage giant cells in antiGBM disease, being absent from the damaged tubulointerstitium. ${ }^{6}$ Furthermore, anti-MMP-12 antibody treatment suppressed renal injury in this model identifying this product of activated macrophages as an important factor in disease pathology. ${ }^{6}$ Thus, downregulation of MMP-12 expression by CC-401 treatment probably reflects an inhibition of the macrophage proinflammatory response. TNF- $\alpha$ is also a major macrophage product which promotes renal injury in this disease model. ${ }^{9,10,34}$ Renal expression of TNF- $\alpha$ and iNOS is restricted to macrophages in the early stages of antiGBM disease, ${ }^{5,34}$ but once tissue damage becomes severe and widespread, both TNF- $\alpha$ and iNOS can be expressed by intrinsic renal cells, including damaged tubular epithelial cells. Thus, preventing upregulation of TNF- $\alpha$ and iNOS on day 24 of anti-GBM disease reflects inhibition of macrophage activation and the suppression of tubulointerstitial damage. In addition, JNK blockade prevented the development of granulomatous lesions with multinucleated macrophage giant cells, a feature of aggressive cell-mediated immunity, despite the presence of numerous macrophages and $\mathrm{T}$ cells in the glomerular tuft. This inhibition of the established macrophage proinflammatory response was associated with halting disease progression as demonstrated by prevention of renal failure, protection from severe renal lesions including crescent formation, and a reduction in the severity of proteinuria.

We identified upregulation of the antiinflammatory molecules IL-10 and HO-1 in untreated crescentic anti-GBM glomerulonephritis. IL-10 administration has been shown to inhibit anti-GBM glomerulonephritis in WKY rats, ${ }^{35,36}$ whereas the induction of anti-GBM glomerulonephritis in IL-10 deficient mice results in more severe disease. ${ }^{37}$ Induction of heme oxygenase-1 expression in macrophages using hemin has been shown to suppress renal injury in rat antiGBM glomerulonephritis. ${ }^{38}$ The upregulation of IL-10 and HO-1 mRNA seen in the vehicle and untreated groups in this study of crescentic anti-GBM glomerulonephritis may reflect a negative feedback mechanism to limit the severity of tissue injury. However, the marked protection seen with CC-401 treatment in anti-GBM glomerulonephritis was associated with a reduction in IL-10 mRNA levels, whereas HO-1 mRNA levels were unchanged, suggesting that JNK blockade did not induce alternative activation of the glomerular macrophage infiltrate-although this is difficult to formally exclude because macrophages can adopt many different states of activation. Furthermore, our in vitro studies identified 

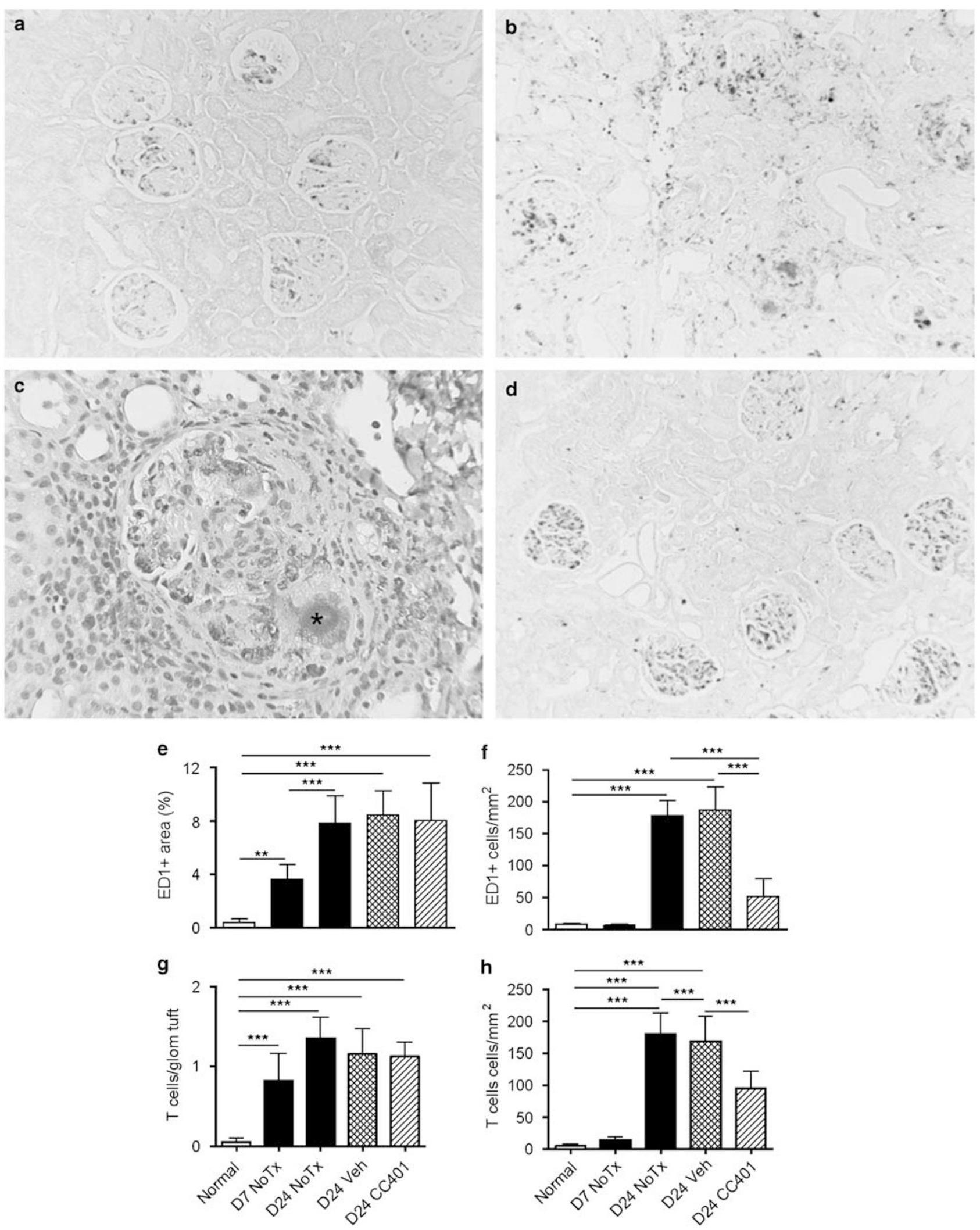
that IL-1 induced upregulation of IL-10 mRNA expression in macrophage is dependent on JNK signaling. Thus, the reduction in IL-10 mRNA levels seen with CC-401 treatment in anti-GBM disease may be a direct effect of JNK inhibition.

Macrophage production of TNF- $\alpha$ and iNOS is known to be dependent on JNK signaling, ${ }^{26,39}$ but the role of JNK in MMP-12 production has not been examined previously. Our studies identified an exquisite sensitivity of the upregulation of MMP-12 mRNA and protein expression to JNK blockade in anti-GBM glomerulonephritis. Furthermore, our in vitro studies identified that IL-1 induction of MMP-12 mRNA and protein was dependent on JNK signaling.

Adaptive immunity, and the Th1 response in particular, plays an important role in directing macrophage-mediated renal injury in the autologous phase of crescentic anti-GBM glomerulonephritis. ${ }^{40,41}$ In this study, JNK blockade was
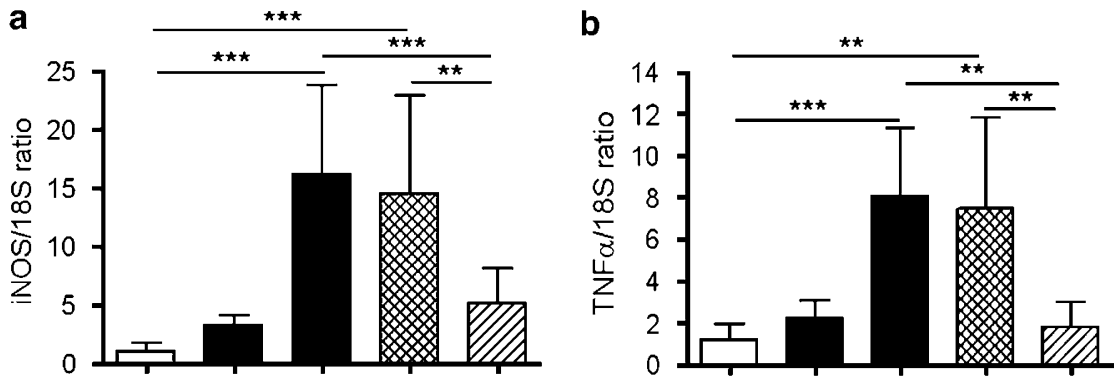

C

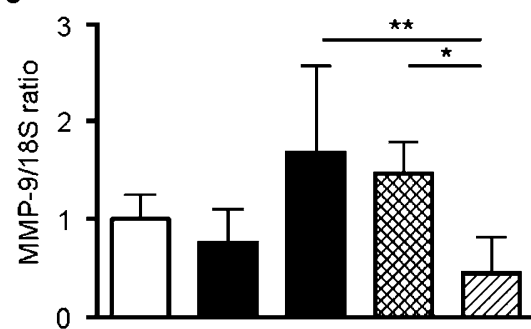

d

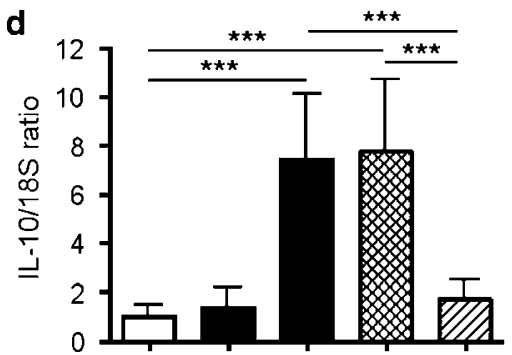

e

f
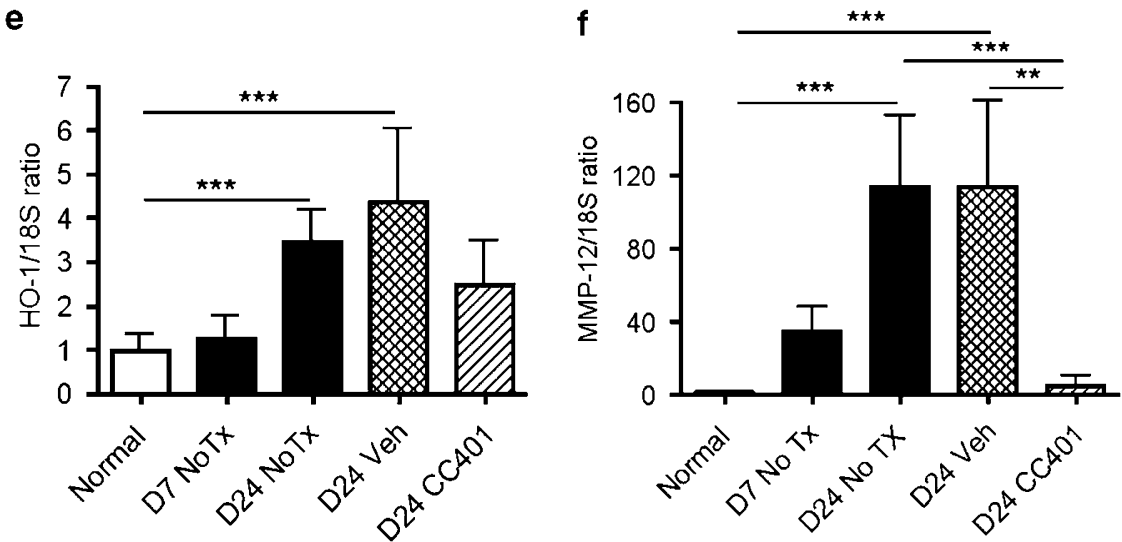

Figure 7 Real-time RT-PCR analysis of pro- and antiinflammatory molecules. Graphs showing relative quantification of mRNA levels in whole kidney tissue for (a) iNOS, (b) TNF- $\alpha$; (c) MMP-9, (d) IL-10, (e) HO-1, and (f) MMP-12. ${ }^{\star} P<0.05,{ }^{* * P}<0.01,{ }^{* * * P<0.001 . ~}$

Figure 6 Macrophage and T-cell infiltration. (a) A significant glomerular infiltrate of ED1 + macrophages is evident on day 7 of untreated disease. (b) By day 24 of untreated disease, there is a substantial increase in macrophage numbers in glomeruli and in the tubulointerstitium, with macrophages also present in crescents and in the periglomerular area. (c) High power view showing the presence of numerous ED1 + macrophages in the capillary tuft and crescent in a single glomerulus. Also note the multinucleated macrophage giant cell $\left(^{*}\right)$ and the many macrophages in the periglomerular area. (d) CC-401 treatment markedly reduced the number of interstitial macrophages, periglomerular macrophages, and macrophages within Bowman's space on day 24 of disease, but there was no effect on the prominent macrophage infiltrate in the glomerular tuft. Graphs showing quantification of ED1 + macrophages in the glomerular tuft (e), and interstitium (f) and quantification of R73 + T cells in the glomerular tuft (g) and interstitium (h). ${ }^{* * P}<0.01,{ }^{* * * P}<0.001$. Original magnification: a, b, d, $\times 160 ; \mathbf{c}, \times 400$. 
a
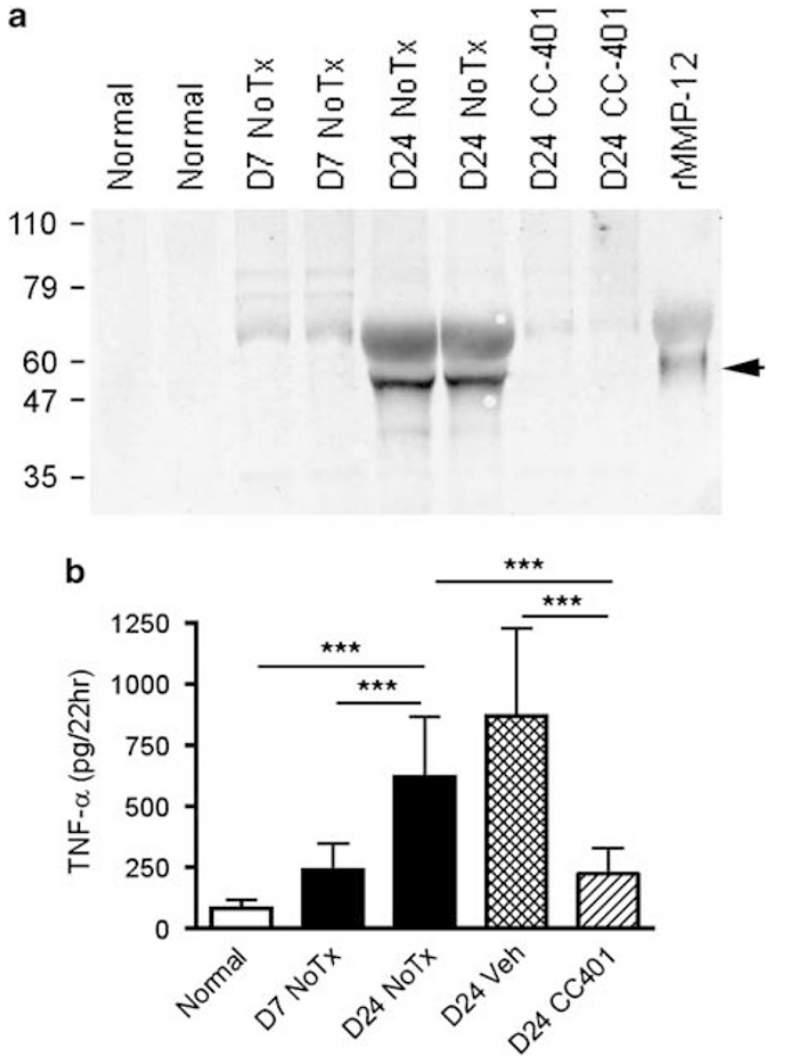

Figure 8 Urinary excretion of proinflammatory molecules. (a) Urine samples were analyzed by western blotting using an antibody that recognizes the $54 \mathrm{kDa}$ precursor form of MMP-12. A tight band of approx $54 \mathrm{kDa}$ was seen in the urine from untreated day 24 anti-GBM disease (arrow), which was absent from the urine of day 24 anti-GBM disease rats given CC-401. A broad nonspecific band above the MMP-12 band is thought to be albumin which is present at high levels in day 24 untreated anti-GBM disease urine and is present as a carrier protein in the recombinant MMP-12 positive control. (b) Urine levels of TNF- $\alpha$ were measured by ELISA. Significant TNF- $\alpha$ levels were seen in urine on day 7 and 24 of anti-GBM disease, which were significant reduced by CC-401 treatment. TNF- $\alpha$ levels in normal rat urine were at the lower limit of detection in this assay $(15 \mathrm{pg} / \mathrm{ml})$. ${ }^{* * *} P<0.001$.

unable to modify the established T- and B-cell immune responses. CC-401 treatment had no effect on the magnitude or Th1/Th2 polarity of the rat IgG response and did not effect glomerular T-cell infiltration. This is consistent with our previous studies showing a lack of effect of JNK blockade on the skin delayed-type hypersensitivity response. ${ }^{27}$ Crescent formation in anti-GBM glomerulonephritis is a cell-mediated immune response involving $\mathrm{T}$ cells and macrophages, ${ }^{2,31}$ and which is dependent on proinflammatory cytokines such as IL-1 and TNF- $\alpha^{9,42}$ Many p-c-Jun stained cells were seen within crescents, consistent with previous studies describing JNK signaling in macrophages and fibroblast-like cells in glomerular crescents. ${ }^{15}$ However, despite the presence of $\mathrm{T}$ cells and many glomerular macrophages, blockade of JNK signaling was highly effective in preventing crescent forma- tion—consistent with an important role for JNK signaling in the macrophage proinflammatory response.

Another novel finding in this study was the demonstration of p-c-Jun serine 63 immunostaining in multinucleated macrophage giant cells. Thus, JNK signaling occurs in multinucleated macrophage giant cells and giant cell formation was prevented by JNK blockade despite the presence of glomerular T cells and macrophages and deposition of rat IgG and C3. Indeed, giant cell formation is prominent in anti-GBM glomerulonephritis in WKY rats, a strain that is highly susceptible to this disease due to a copy number polymorphism in the gene for the $\mathrm{Fc}-\gamma$ receptor III which results in macrophage 'overactivity. ${ }^{43}$ These findings may be directly linked because Fc- $\gamma$ receptor blockade has been shown to ameliorate the formation of multinucleated giant cells in experimental myocarditis. ${ }^{44}$ Furthermore, Fc- $\gamma$ receptor engagement on macrophages induces JNK signaling, ${ }^{45,46}$ which may be one contributing factor to the dramatic inhibition of crescentic anti-GBM glomerulonephritis seen with JNK blockade.

Modulation of the macrophage proinflammatory response is not the only possible mechanism by which JNK blockade prevented severe glomerular lesions and halted disease progression. Glomerular cells other than macrophages are positive for p-c-Jun immunostaining in anti-GBM glomerulonephritis, such as podocytes. ${ }^{27}$ Although virtually nothing is known of the role of JNK signaling in podocytes, it could be postulated that JNK blockade may inhibit podocyte damage and apoptosis and thereby reduce glomerular damage. Activation of glomerular mesangial cells, as shown by induction of a mesangial-like $\alpha$-SMA expression pattern, was unaltered by CC- 401 treatment suggesting no role for JNK signaling in this aspect of the glomerular response to injury.

The prevention of tubulointerstitial injury seen with JNK blockade in anti-GBM glomerulonephritis may operate via direct and/or indirect mechanisms. Tubulointerstitial injury in anti-GBM glomerulonephritis is secondary to glomerular damage and the development of proteinuria. ${ }^{47}$ Intervention treatment with CC-401 was highly effective in suppressing progressive glomerular damage and proteinuria, thereby indirectly removing much of the stimulus for tubulointerstitial injury. However, glomerular and tubular JNK signaling and proteinuria were already increased at day 7 when CC-401 treatment was begun. A number of in vitro studies have demonstrated a direct role for JNK signaling in angiotensin II induced TGF- $\beta 1$ production in tubular epithelial cells and in TGF- $\beta 1$ and albumin induced upregulation of $\alpha 1$-collagen and MCP-1 mRNA, ${ }^{16,30}$ whereas in vivo studies have shown that JNK blockade can suppress interstitial fibrosis and tubular apoptosis in the obstructed kidney. ${ }^{30}$ Furthermore, JNK blockade prevents tubular damage following renal ischemia/ reperfusion injury. ${ }^{48}$ Thus, JNK blockade may exert a direct effect to reduce the degree of tubulointerstitial damage in rat anti-GBM glomerulonephritis.

In summary, this study demonstrates that JNK blockade provides profound protection from glomerular lesions and 

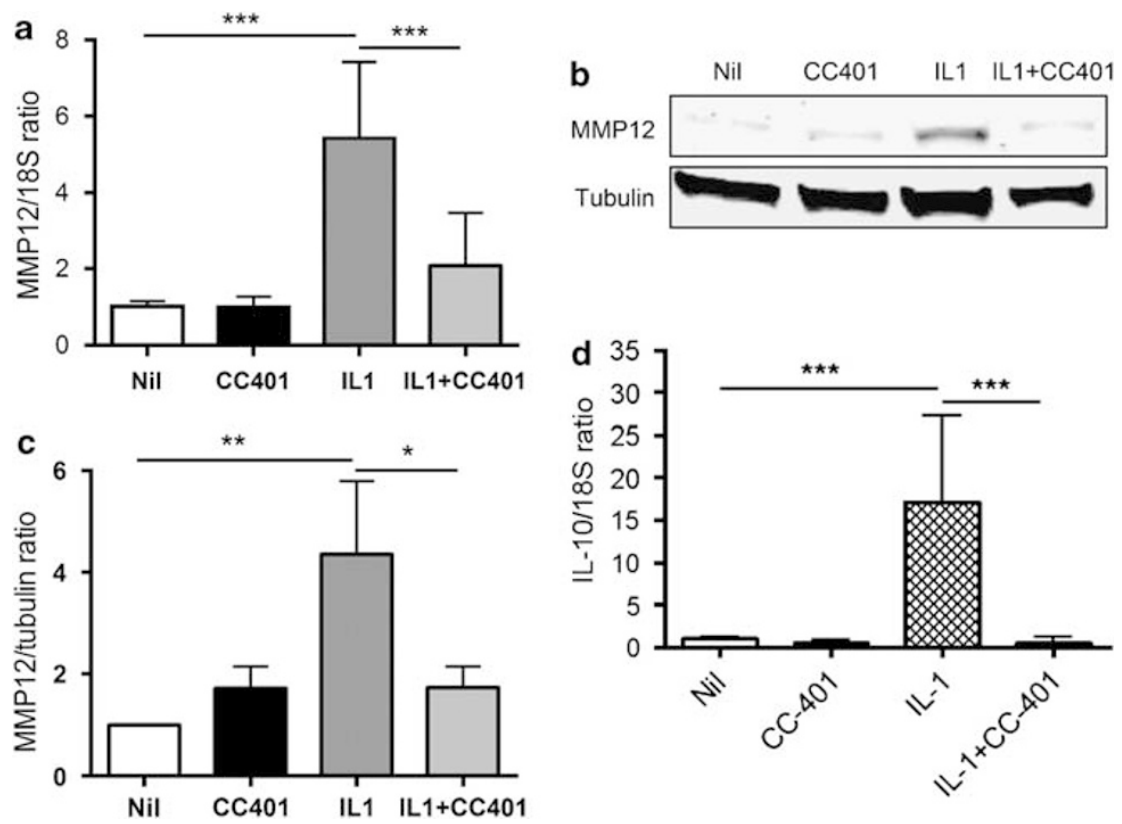

Figure 9 IL-1 induced MMP-12 expression is JNK dependent. U937 human monocytes were cultured and differentiated with the presence of PMA and GMCSF. Cells were stimulated with $10 \mathrm{ng} / \mathrm{ml} \mathrm{IL-1} \beta$ in the presence or absence of $4 \mu \mathrm{M} \mathrm{CC}-401 \mathrm{for} 24 \mathrm{~h}$ (a) or $48 \mathrm{~h}$ (b). Analysis of MMP- $12 \mathrm{was}$ performed by realtime RT-PCR (a). MMP-12 protein levels in U937 cell lysates was examined by western blotting (b), with results analyzed by densitometry (c). (d) RAW macrophages were cultured in the presence or absence of $4 \mu \mathrm{M} \mathrm{CC}-401$ for $30 \mathrm{~min}$ before a $16 \mathrm{~h}$ stimulation with IL-1 $\beta$. Analysis of IL-10 mRNA was performed by real-time RT-PCR. ${ }^{\star} P<0.05,{ }^{* *} P<0.01,{ }^{* * *} P<0.001$.

halts disease progression in rat anti-GBM glomerulonephritis. Downregulation of the macrophage proinflammatory response is one of several possible mechanisms by which JNK blockade exerted these beneficial effects. Furthermore, we have identified novel roles for JNK signaling in the development of macrophage multinucleated giant cells and in macrophage MMP-12 and IL-10 production.

\section{ACKNOWLEDGEMENTS}

This study was funded by the National Health and Medical Research Council of Australia, Kidney Health Australia, and by Celgene, San Diego, USA.

\section{DISCLOSURE}

A financial conflict of interest may exist because Celgene in part funded this study and DN-P acts as a consultant for Celgene.

1. Nikolic-Paterson DJ, Atkins RC. The role of macrophages in glomerulonephritis. Nephrol Dial Transplant 2001;16(Suppl 5):3-7.

2. Atkins RC, Nikolic-Paterson DJ, Song Q, et al. Modulators of crescentic glomerulonephritis. J Am Soc Nephrol 1996;7:2271-2278.

3. Takemura T, Yoshioka K, Murakami K, et al. Cellular localization of inflammatory cytokines in human glomerulonephritis. Virchows Arch 1994;424:459-464.

4. Tesch GH, Yang N, Yu H, et al. Intrinsic renal cells are the major source of interleukin-1 beta synthesis in normal and diseased rat kidney. Nephrol Dial Transplant 1997;12:1109-1115.

5. Bremer V, Tojo A, Kimura K, et al. Role of nitric oxide in rat nephrotoxic nephritis: comparison between inducible and constitutive nitric oxide synthase. J Am Soc Nephrol 1997;8:1712-1721.

6. Kaneko $Y$, Sakatsume M, Xie Y, et al. Macrophage metalloelastase as a major factor for glomerular injury in anti-glomerular basement membrane nephritis. J Immunol 2003;170:3377-3385.
7. Tipping PG, Lowe MG, Holdsworth SR. Glomerular macrophages express augmented procoagulant activity in experimental fibrinrelated glomerulonephritis in rabbits. J Clin Invest 1988;82:1253-1259.

8. Lan HY, Nikolic-Paterson DJ, Zarama M, et al. Suppression of experimental crescentic glomerulonephritis by the interleukin-1 receptor antagonist. Kidney Int 1993;43:479-485.

9. Lan HY, Yang N, Metz C, et al. TNF-alpha up-regulates renal MIF expression in rat crescentic glomerulonephritis. Mol Med 1997;3:136-144.

10. Le Hir M, Haas C, Marino $M$, et al. Prevention of crescentic glomerulonephritis induced by anti-glomerular membrane antibody in tumor necrosis factor-deficient mice. Lab Invest 1998;78:1625-1631.

11. Lan HY, Nikolic-Paterson DJ, Mu W, et al. Local macrophage proliferation in multinucleated giant cell and granuloma formation in experimental Goodpasture's syndrome. Am J Pathol 1995;147: $1214-1220$.

12. Rastaldi MP, Ferrario F, Crippa A, et al. Glomerular monocytemacrophage features in ANCA-positive renal vasculitis and cryoglobulinemic nephritis. J Am Soc Nephrol 2000;11:2036-2043.

13. Frosch M, Vogl T, Waldherr R, et al. Expression of MRP8 and MRP14 by macrophages is a marker for severe forms of glomerulonephritis. J Leukoc Biol 2004:75:198-206.

14. Ikezumi Y, Suzuki T, Hayafuji S, et al. The sialoadhesin (CD169) expressing a macrophage subset in human proliferative glomerulonephritis. Nephrol Dial Transplant 2005;20:2704-2713.

15. Stambe C, Atkins RC, Hill PA, et al. Activation and cellular localization of the p38 and JNK MAPK pathways in rat crescentic glomerulonephritis. Kidney Int 2003;64:2121-2132.

16. De Borst MH, Prakash J, Melenhorst WB, et al. Glomerular and tubular induction of the transcription factor c-Jun in human renal disease. J Pathol 2007;213:219-228.

17. Stambe C, Nikolic-Paterson DJ, Hill PA, et al. p38 Mitogen-activated protein kinase activation and cell localization in human glomerulonephritis: correlation with renal injury. J Am Soc Nephrol 2004; 15:326-336.

18. Sakai N, Wada T, Furuichi K, et al. p38 MAPK phosphorylation and NFkappa B activation in human crescentic glomerulonephritis. Nephrol Dial Transplant 2002;17:998-1004. 
19. Gordon S. Alternative activation of macrophages. Nat Rev Immunol 2003;3:23-35.

20. Erwig LP, Stewart K, Rees AJ. Macrophages from inflamed but not normal glomeruli are unresponsive to anti-inflammatory cytokines. Am J Pathol 2000;156:295-301.

21. Nishida $M$, Okumura $Y$, Fujimoto $S$, et al. Adoptive transfer of macrophages ameliorates renal fibrosis in mice. Biochem Biophys Res Commun 2005;332:11-16.

22. Vinuesa $E$, Hotter $G$, Jung $M$, et al. Macrophage involvement in the kidney repair phase after ischaemia/reperfusion injury. J Pathol 2008;214:104-113.

23. Kluth DC, Erwig LP, Rees AJ. Multiple facets of macrophages in renal injury. Kidney Int 2004;66:542-557.

24. Wilson HM, Chettibi S, Jobin C, et al. Inhibition of macrophage nuclear factor-kappaB leads to a dominant anti-inflammatory phenotype that attenuates glomerular inflammation in vivo. Am J Pathol 2005; 167:27-37.

25. Wang Y, Wang YP, Zheng G, et al. Ex vivo programmed macrophages ameliorate experimental chronic inflammatory renal disease. Kidney Int 2007;72:290-299.

26. Ikezumi $\mathrm{Y}$, Hurst L, Atkins RC, et al. Macrophage-mediated renal injury is dependent on signaling via the JNK pathway. J Am Soc Nephrol 2004; 15:1775-1784.

27. Flanc RS, Ma FY, Tesch GH, et al. A pathogenic role for JNK signaling in experimental anti-GBM glomerulonephritis. Kidney Int 2007;72: $698-708$.

28. Uehara T, Xi Peng X, Bennett B, et al. c-Jun N-terminal kinase mediates hepatic injury after rat liver transplantation. Transplantation 2004;78:324-332.

29. Wu L, Fan J, Matsumoto $S$, et al. Induction and regulation of matrix metalloproteinase-12 by cytokines and CD40 signaling in monocyte/macrophages. Biochem Biophys Res Commun 2000;269:808-815.

30. Ma FY, Flanc RS, Tesch GH, et al. A Pathogenic Role for c-Jun AminoTerminal Kinase Signaling in Renal Fibrosis and Tubular Cell Apoptosis. J Am Soc Nephrol 2007;18:472-484.

31. Kitching AR, Holdsworth SR, Tipping PG. Crescentic glomerulonephritis - a manifestation of a nephritogenic Th1 response? Histol Histopathol 2000;15:993-1003.

32. Martinez FO, Sica A, Mantovani A, et al. Macrophage activation and polarization. Front Biosci 2008;13:453-461.

33. Willis $D$, Moore AR, Frederick $R$, et al. Heme oxygenase: a novel target for the modulation of the inflammatory response. Nat Med 1996;2:87-90.

34. Tipping PG, Leong TW, Holdsworth SR. Tumor necrosis factor production by glomerular macrophages in anti-glomerular basement membrane glomerulonephritis in rabbits. Lab Invest 1991;65:272-279.
35. Huang XR, Kitching AR, Tipping PG, et al. Interleukin-10 inhibits macrophage-induced glomerular injury. J Am Soc Nephrol 2000;11:262-269.

36. El-Shemi AG, Fujinaka H, Matsuki A, et al. Suppression of experimental crescentic glomerulonephritis by interleukin-10 gene transfer. Kidney Int 2004;65:1280-1289.

37. Kitching AR, Tipping PG, Timoshanko JR, et al. Endogenous interleukin10 regulates Th1 responses that induce crescentic glomerulonephritis. Kidney Int 2000;57:518-525.

38. Datta PK, Duann P, Lianos EA. Long-term effect of heme oxygenase (HO)-1 induction in glomerular immune injury. J Lab Clin Med 2006;147:150-155.

39. Chan ED, Riches DW. IFN-gamma + LPS induction of iNOS is modulated by ERK, JNK/SAPK, and p38(mapk) in a mouse macrophage cell line. Am J Physiol Cell Physiol 2001;280:C441-C450.

40. Huang XR, Tipping PG, Apostolopoulos J, et al. Mechanisms of T cellinduced glomerular injury in anti-glomerular basement membrane (GBM) glomerulonephritis in rats. Clin Exp Immunol 1997;109:134-142.

41. Reynolds J, Tam FW, Chandraker A, et al. CD28-B7 blockade prevents the development of experimental autoimmune glomerulonephritis. J Clin Invest 2000;105:643-651.

42. Lan HY, Nikolic-Paterson DJ, Mu W, et al. Interleukin-1 receptor antagonist halts the progression of established crescentic glomerulonephritis in the rat. Kidney Int 1995;47:1303-1309.

43. Aitman TJ, Dong R, Vyse TJ, et al. Copy number polymorphism in Fcgr3 predisposes to glomerulonephritis in rats and humans. Nature 2006;439:851-855

44. Shioji K, Kishimoto C, Sasayama S. Fc receptor-mediated inhibitory effect of immunoglobulin therapy on autoimmune giant cell myocarditis: concomitant suppression of the expression of dendritic cells. Circ Res 2001;89:540-546.

45. Rose DM, Winston BW, Chan ED, et al. Interferon-gamma and transforming growth factor-beta modulate the activation of mitogenactivated protein kinases and tumor necrosis factor-alpha production induced by Fc gamma-receptor stimulation in murine macrophages. Biochem Biophys Res Commun 1997;238:256-260.

46. Rose DM, Winston BW, Chan ED, et al. Fc gamma receptor cross-linking activates p42, p38, and JNK/SAPK mitogen-activated protein kinases in murine macrophages: role for p42MAPK in Fc gamma receptorstimulated TNF-alpha synthesis. J Immunol 1997;158:3433-3438.

47. Lan HY, Paterson DJ, Atkins RC. Initiation and evolution of interstitial leukocytic infiltration in experimental glomerulonephritis. Kidney Int 1991;40:425-433.

48. Wang Y, Ji HX, Xing SH, et al. SP600125, a selective JNK inhibitor, protects ischemic renal injury via suppressing the extrinsic pathways of apoptosis. Life Sci 2007;80:2067-2075. 